CZASOPISMO INŻYNIERII LĄDOWEJ, ŚRODOWISKA I ARCHITEKTURY JOURNAL OF CIVIL ENGINEERING, ENVIRONMENT AND ARCHITECTURE

JCEEA, t. XXXIV, z. 64 (1/17), styczeń-marzec 2017, s. 423-430, DOI:10.7862/rb.2017.38

\author{
Paweł WAJSS ${ }^{1}$ \\ Mariusz FILIPOWICZ2
}

\title{
CHARAKTERYSTYKA HELIOSTATÓW I ICH ZASTOSOWANIE W HELIOELEKTROWNIACH
}

\begin{abstract}
Rozwój energetyki słonecznej związany jest z powstawaniem coraz to nowych konstrukcji maksymalizującej wykorzystanie promieniowania słonecznego. Jednym z kierunków jest wysokotemperaturowa konwersja promieniowania na ciepło. Wtedy, z termodynamicznego punktu widzenia otwierają się nam możliwości np. na generację energii elektrycznej. Konwersja wysokotemperaturowa wymaga jednak koncentracji promieniowania słonecznego. Sposobów koncentracji jest wiele, jednak w artykule skupiono się na koncentracji w układzie pole heliostatów- wieża słoneczna. System taki ma szereg zalet w porównaniu do pojedynczych układów koncentrujących, m.in. możliwe jest budowanie pojedynczej elektrowni. Zasadniczym elementem jest tutaj heliostat. Artykuł definiuje pojęcie heliostatu, przedstawia zasadę jego działania oraz przeznaczenie w helioelektrowniach typu wieżowego. Dokonany został podział urządzeń na podgrupy w zależności od technologii w nich zastosowanych. Zaprezentowane zostały poszczególne elementy budowy heliostatów oraz czynniki, które pośrednio lub bezpośrednio wpływają na ich typ, wielkość oraz cenę. Przedstawiono problematykę rentowności przed jaką stoi dziś rynek helioelektrowni oraz stopień istotności jaki stanowi pole heliostatów dla budżetu całej inwestycji. Wymieniono szczegółowe parametry jakie winny spełniać tego typu urządzenia, z wyodrębnieniem trzech grup: wymagania operacyjne, optyczne oraz wytrzymałościowe. Zaprezentowano szczegółowo trzy przykładowe, znacząco różniące co do zasady działania oraz skali, rozwiązania i sparametryzowano je w formie tabelarycznej.
\end{abstract}

Słowa kluczowe: energetyka słoneczna, skoncentrowane promieniowanie słoneczne, układy nadążne, tracking

\section{Wprowadzenie}

Heliostaty są urządzeniami, które podążają za pozornym ruchem słońca po nieboskłonie, wyposażone w zwierciadła płaskie, lub o bardzo małej krzywiźnie (ogniskowej rzędu dziesiątek do nawet kilku tysięcy metrów), których celem jest odbicie bezpośredniego promieniowania słonecznego i skierowanie go w ściśle

${ }^{1}$ Autor do korespondencji / corresponding author: Paweł Wajss, Wydział Energetyki i Paliw, Akademia Górniczo-Hutnicza im. Stanisława Staszica w Krakowie, tel. 1261734 28, wajss@agh.edu.pl

${ }^{2}$ Mariusz Filipowicz, Wydział Energetyki i Paliw, Akademia Górniczo-Hutnicza im. Stanisława Staszica w Krakowie, tel. 1261751 92, filipow@agh.edu.pl 
określony, niezmienny co do położenia, punkt. W związku z tym są niezbędnym elementem helioelektrowni typu wieżowego przedstawionej na rys. 1 . W helioelektrowniach obszarem, na które kierowane jest promieniowanie jest szczyt wieży, gdzie umieszczony jest specjalny odbiornik, którego zadaniem jest konwersja przekserowanego z wielu heliostatów promieniowania słonecznego na ciepło. Ciepło to dalej w cyklu Rankine'a jest przetwarzane na energię elektryczną stąd nazwa samego systemu: helioelektrownia. Choć zasadniczo sama koncepcja systemu wydaję się prosta wiąże się $\mathrm{z}$ nią wiele zagadnień, które nadal podlegają rozważaniom w światowych jednostkach badawczych. Budowa wieży o wysokości kilkudziesięciu metrów nie stanowi wyzwania w dzisiejszym świecie budowy obiektów inżynieryjnych, natomiast złożenie, montaż oraz synchronizowanie heliostatów liczonych nawet setkach tysięcy sztuk, o wielkości apertury od kilku do $150 \mathrm{~m}^{2} /$ heliostat, dla pojedynczej inwestycji stanowi nie lada wyzwanie zarówno w czasie budowy i użytkowania helioelektrowni ale także na etapie jej projektowania. Każdy z heliostatów to niezależne urządzenie (choć są rozwiązania łączące je w grupy, np. [1]) musi zatem posiadać swój własny system napędowy, kontroli położenia, a także diagnostyki. To przekłada się bezpośrednio na koszty takiego urządzenia. Przenosząc to na skalę całej inwestycji, budowa i uruchomienie pola heliostatów obciąża ok $40 \%$ całego budżetu inwestycji, co stanowi największy jednostkowy udział kosztów [2]. Obsługa pola heliostatów, tj. czyszczenie zwierciadeł oraz doraźna naprawa stanowi również największy udział kosztów w zakresie utrzymania helioelektrowni [2]. Stąd też usilne próby środowisk naukowych w celu znalezienia rozwiązania, które jedno-

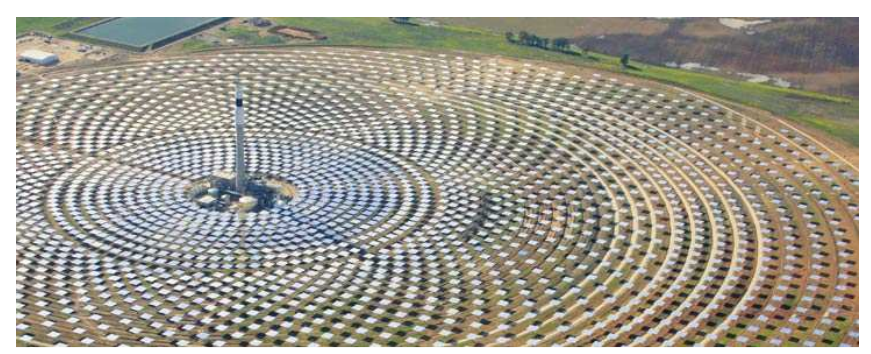
cześnie przyczyni się do redukcji kosztów produkcji ale i utrzymania heliostatów, a przez to przyczyni się do rozwoju tej technologii.

Rys. 1. Helioelektrownia typu wieżowego, pole heliostatów otacza wieżę słoneczną ze wszystkich stron, źródło: EcoGuard

Fig. 1. Solar power tower with surrounding field of heliostats, source: EcoGuard

\section{Heliostaty}

\subsection{Budowa heliostatu}

Heliostaty, jak przedstawiono na rys. 2 składają się z następujących części: - podstawy + fundamentów (3), 
- napędów do zmiany kąta elewacji i azymutu (2),

- zwierciadła + konstrukcji nośnej (1).

Rys. 2. Budowa heliostatu, źródło: eSolar Fig. 2. Construction of heliostat, source: eSolar

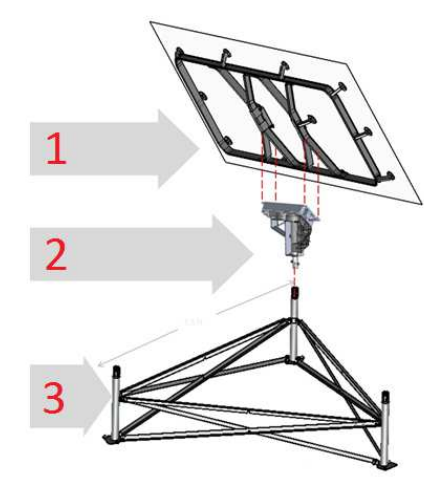

Zadaniem fundamentów i podstawy jest umocowanie heliostatu do podłoża i zagwarantowanie, że nie zmieni on swojego położenia w całym cyklu życia heliostatu tj. 20-30 lat w zależności od konstrukcji. Czyni się to przez różne sposoby w zależności od podłoża. Pod duże heliostaty (powyżej $50 \mathrm{~m}^{2}$ apertury) stosuje się fundament betonowy, dla heliostatów w zakresie $5-50 \mathrm{~m}^{2}$ apertury zastosować można pale wbijane w ziemię (na głębokość równą wysokości heliostatu), natomiast dla najmniejszych heliostatów $\left(\leq 5 \mathrm{~m}^{2}\right)$ stosuje się kotwy, jeżeli pozwalają na to warunki podłoża. Stosuje się również rozwiązanie łączenia małych heliostatów w grupy dzięki czemu przy ich małej wysokości i relatywnie dużego ciężaru własnego nie jest wymagany żaden dodatkowy element łączący fizycznie heliostaty z podłożem. Zadaniem konstrukcji nośnej i napędów jest stabilne utrzymywanie i precyzyjne pozycjonowanie fasety (zwierciadła). Są to bardzo istotne elementy, gdyż ich prawidłowe funkcjonowanie jest uzależnione od odporności na oddziaływanie zewnętrznych warunków atmosferycznych. Konstrukcja nośna fasety stanowi również ważny element $\mathrm{w}$ trakcie kalibracji optycznej zwierciadła tj. tak jego ustawiania aby obraz na odbiorniku był jak najbardziej skoncentrowany i pozbawiony błędów. Napęd jest w przypadku wielu typów heliostatów najdroższym elementem przy czym można je podzielić na dwie główne grupy w zależności od źródła zasilania: silniki elektromagnetyczne oraz siłowniki hydrauliczne. W zależności od wielkości i rodzaju heliostatu zastosowanie znajduje różny napęd. Możemy wyróżnić konkretne rozwiązania tj. przekładnie ślimakowe, przekładnie zębate, przekładnie łańcuchowe, przekładnie falowe, Capstan, przekładania planetarna, siłowniki liniowe oraz koła cierne. Mechanizm ten musi być na tyle precyzyjny aby światło odbite padało na odbiornik ulokowany w odległości nawet kilku kilometrów od zwierciadła, przy tym zachowując odporność na oddziaływanie warunków atmosferycznych. Poszczególne wymagania opisane są w tab.1 
Tabela 1. Wymagania stawiane wobec podsystemów heliostatu, na podstawie [3]

Table 1. Heliostat's subsystems requirements, based on [3]

\begin{tabular}{|c|c|c|c|}
\hline \multicolumn{2}{|r|}{ Wymagania } & Wartość oczekiwane & System \\
\hline \multirow{6}{*}{ 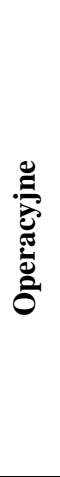 } & Tryby pracy & $\begin{array}{l}\text { Normalny (śledzenie precyzyjne), Zre- } \\
\text { dukowany (śl. nieprecyzyjne), Pozycja } \\
\text { na żąanie (postój), Pozycja bezpieczna }\end{array}$ & Oprogramowanie \\
\hline & Wiatr & $\begin{array}{l}\text { Śledzenie do } 15,6 \mathrm{~m} / \mathrm{s} \text {; parkowanie do } \\
22,5 \mathrm{~m} / \mathrm{s}\end{array}$ & $\begin{array}{l}\text { Napędy + konstruk- } \\
\text { cja nośna }\end{array}$ \\
\hline & $\begin{array}{l}\text { Awaryjne rozogni- } \\
\text { skowanie }\end{array}$ & 3 minuty & $\begin{array}{l}\text { Napędy + konstruk- } \\
\text { cja nośna }\end{array}$ \\
\hline & $\begin{array}{l}\text { Maks. czas ruchu do } \\
\text { poz. bezpiecznej }\end{array}$ & Brak danych & Napędy \\
\hline & $\begin{array}{l}\text { Własne potrzeby } \\
\text { energetyczne }\end{array}$ & Brak danych & Napędy \\
\hline & $\begin{array}{l}\text { Zakres dla azymutu i } \\
\text { elewacji }\end{array}$ & Brak danych & Napędy + podstawa \\
\hline \multirow{5}{*}{$\frac{\pi}{0}$} & $\begin{array}{l}\text { Celność wiązki } \\
\text { światła odbitego }\end{array}$ & $\begin{array}{l}\text { Maksimum } 1,5 \text { mrad średnia kwadra- } \\
\text { towa (odchylenie st.) dla każdej z osi }\end{array}$ & $\begin{array}{l}\text { Oprogramowanie }+ \\
\text { napędy }\end{array}$ \\
\hline & Jakość wiązki & $\begin{array}{l}\text { Kształt teoretyczny }+1,4 \text { mrad po ob- } \\
\text { wodzie w zakresie temperatur } 0-50 \text { st.C }\end{array}$ & $\begin{array}{l}\text { Zwierciadło + kon- } \\
\text { strukcja nośna }\end{array}$ \\
\hline & $\begin{array}{l}\text { Odkszt. spowodo- } \\
\text { wane wiatrem }\end{array}$ & $\begin{array}{l}\text { Maksimum } 3,6 \text { mrad średnia kwadra- } \\
\text { towa na zwierciadle }\end{array}$ & $\begin{array}{l}\text { Konstrukcja nośna + } \\
\text { napędy }\end{array}$ \\
\hline & $\begin{array}{l}\text { Odkształcania fun- } \\
\text { damentu }\end{array}$ & $\begin{array}{l}\text { Maks. } 0,45 \mathrm{mrad} \text { średnia kwadratowa } \\
\text { przy porywistych wiatrach } \\
\text { Maks. } 1,5 \mathrm{mrad} \text { przekręcenia lub po- } \\
\text { chylania przy prędkości wiatru } 12 \mathrm{~m} / \mathrm{s}\end{array}$ & $\begin{array}{l}\text { Podstawa }+ \text { kon- } \\
\text { strukcja nośna }+ \\
\text { napędy }+ \text { zwierciadła }\end{array}$ \\
\hline & $\begin{array}{l}\text { Refleksyjność, spa- } \\
\text { dek refleks. w funk- } \\
\text { cji czasu i ilości myć }\end{array}$ & $\begin{array}{l}95-96 \% \text { (cel do 2025) aktualnie } \\
93-94 \% \text {, dla spadku brak danych }\end{array}$ & Zwierciadła \\
\hline \multirow{6}{*}{ 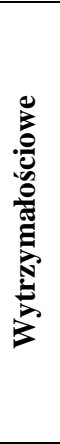 } & Prędkość wiatru & $\begin{array}{l}22,35 \mathrm{~m} / \mathrm{s} \text { dla dowolnego położenia } \\
40,23 \mathrm{~m} / \mathrm{s} \text { dla pozycji bezpiecznej }\end{array}$ & Wszystkie części \\
\hline & Temperatura & -29 st.C -50 st.C & Zwierciadła \\
\hline & Grad & $\begin{array}{l}\varnothing 1,8 \mathrm{~cm} \mathrm{z} \text { prędkością } 20 \mathrm{~m} / \mathrm{s} \text { w do- } \\
\text { wolnej pozycji oraz } \emptyset 2,5 \mathrm{~cm} \text { z prędko- } \\
\text { ścią } 22,5 \mathrm{~m} / \mathrm{s} \text { dla pozycji bezpiecznej }\end{array}$ & Zwierciadła \\
\hline & $\begin{array}{l}\text { Piasek (burze pia- } \\
\text { skowe) }\end{array}$ & Odporność na zarysowania i tarcia & $\begin{array}{l}\text { Zwierciadła + napę- } \\
\text { dy }\end{array}$ \\
\hline & Mycie & $\begin{array}{l}\text { Odporność na szok termiczny (zimna } \\
\text { woda) }\end{array}$ & $\begin{array}{l}\text { Wszystkie części } \\
\text { mechaniczne }\end{array}$ \\
\hline & Czas życia & $\begin{array}{l}30 \text { lat uwzględniając małe naprawy } \\
\text { oraz poprawne utrzymanie }\end{array}$ & Wszystkie części \\
\hline
\end{tabular}

Niebagatelny wpływ na typ konstrukcji oraz jego budowę ma wielkość oraz rodzaj zwierciadła Powierzchnie faset (pojedynczych zwierciadeł) mieszczą się w granicach 1-10 $\mathrm{m}^{2}$. Zwierciadła muszą charakteryzować się możliwie największą refleksyjnością dla całego widma, mieć możliwie mały ciężar właściwy oraz długą żywotność przy niskich kosztach obsługi. Wyróżniamy trzy główne typy zwierciadeł: 
- standardowe szkło o gr. $4 \mathrm{~mm} \mathrm{z}$ warstwą refleksyjną od tyłu zabezpieczone antykorozyjnie oraz przed wilgocią,

- szkło cienkowarstwowe o gr. $<1 \mathrm{~mm}$ z warstwą refleksyjną od tyłu lub po środku w rozwiązaniu typu sandwich, oraz

- membrany refleksyjne naciągane na ramy.

Prowadzone są również badania nad polimerami, które w przyszłości mogą zastąpić w/w materiały. Charakterystykę trzech przykładowych heliostatów o różnej konstrukcji przedstawiono w tabeli 2 oraz na rysunkach 3, 4 i 5.

Tabela 2. Parametry heliostatów, na podstawie [4] i [5]

Table 2. Heliostats' parameters, based on [4] and [5]

\begin{tabular}{|c|c|c|c|}
\hline Heliostat & ASM 150 & Colon 70 & Helio 40 \\
\hline Wymiary apertury [m] & $\varnothing \sim 14 \mathrm{~m}$ & H 7,82 m x W 9,04 m & $\mathrm{H} 1,41 \mathrm{~m} \times \mathrm{W}$ 1,41 m \\
\hline $\begin{array}{l}\text { Powierzchnia faset } \\
\text { [m2], ilość [szt.] }\end{array}$ & $\begin{array}{l}150 \mathrm{~m}^{2} \times 1 \text { szt. }= \\
150 \mathrm{~m}^{2}\end{array}$ & $\begin{array}{l}3,3 \mathrm{~m}^{2} \times 21 \mathrm{szt} .= \\
69,3 \mathrm{~m}^{2}\end{array}$ & $\begin{array}{l}2 \mathrm{~m}^{2} \times 1 \text { szt. }= \\
2 \mathrm{~m}^{2}\end{array}$ \\
\hline $\begin{array}{l}\text { Konstrukcja pod } \\
\text { zwierciadła }\end{array}$ & $\begin{array}{l}\text { Metaliczna nacią- } \\
\text { gnięta membrana }\end{array}$ & $\begin{array}{l}\text { Zwierciadło mocowane } \\
\text { do stalowej ramy }\end{array}$ & $\begin{array}{l}\text { Zwierciadło mocowane } \\
\text { do stalowej ramy }\end{array}$ \\
\hline Zwierciadło & $\begin{array}{l}0,9 \text { mm szkło cien- } \\
\text { kowarstwowe }\end{array}$ & $\begin{array}{l}4 \mathrm{~mm} \text { szkło, } \\
\text { producent: Pilkington }\end{array}$ & 4 mm szkło \\
\hline Refleksyjność [\%] & 94 & $92-93$ & Brak danych \\
\hline Napęd azymutu & $\begin{array}{l}\text { Elektrycznie napę- } \\
\text { dzana obrotnica z } \\
\text { enkoderem }\end{array}$ & $\begin{array}{l}\text { Przekładnia ślimakowa, } \\
\text { producent: Winsmith }\end{array}$ & $\begin{array}{l}\text { Przekładnia ślimakowa } \\
\text { + przekładnia plane- } \\
\text { tarna }\end{array}$ \\
\hline Napęd elewacji & $\begin{array}{l}\text { Elektrycznie napę- } \\
\text { dzane koło szpry- } \\
\text { chowe z enkoderem }\end{array}$ & $\begin{array}{l}\text { Przekładnia ślimakowa, } \\
\text { producent: Winsmith }\end{array}$ & Siłownik liniowy \\
\hline $\begin{array}{l}\text { Przełożenia napędów } \\
(\mathrm{Az} / \mathrm{El})\end{array}$ & Brak danych & \begin{tabular}{|l|} 
Az 18.000:1 \\
El 18.000:1
\end{tabular} & Az 35.650:1 \\
\hline Typ kontrolera & $\begin{array}{l}\text { Sygnał PWM, roz- } \\
\text { dzielczość } 40.000 \\
\text { kroków / } 360^{\circ} \\
\end{array}$ & $\begin{array}{l}\text { Kontrolery lokalne i } \\
\text { nadrzędne }\end{array}$ & Brak danych \\
\hline Typ podstawy & $\begin{array}{l}\text { Platforma na beto- } \\
\text { nowym pierścieniu + } \\
\text { rdzeń }\end{array}$ & Rura stalowa $\varnothing 0,5 \mathrm{~m}$ & $\begin{array}{l}\text { Wolnostojące metalo- } \\
\text { we kratownice }\end{array}$ \\
\hline Waga (bez fund.) [kg] & $3.300\left(22 \mathrm{~kg} / \mathrm{m}^{2}\right)$ & $4.000\left(57,7 \mathrm{~kg} / \mathrm{m}^{2}\right)$ & $78\left(39 \mathrm{~kg} / \mathrm{m}^{2}\right)$ \\
\hline $\begin{array}{l}\text { Badanie odporności na } \\
\text { wiatr }\end{array}$ & $\begin{array}{l}\text { Śledzenie: od } 5 \mathrm{~m} / \mathrm{s} \\
\text { do } 16,7 \mathrm{~m} / \mathrm{s} \\
\text { Maks.: } 40,3 \mathrm{~m} / \mathrm{s} \\
\end{array}$ & Brak danych & $\begin{array}{l}\text { Śledzenie: od } 5,5 \mathrm{~m} / \mathrm{s} \\
\text { do } 13,9 \mathrm{~m} / \mathrm{s} \\
\text { Maks.: } 27,8 \mathrm{~m} / \mathrm{s}\end{array}$ \\
\hline $\begin{array}{l}\text { Badanie precyzji pozy- } \\
\text { cjonowania [mrad] }\end{array}$ & $\begin{array}{l}0,52-0,7 \text { odchylenia } \\
\text { standardowego }\end{array}$ & Brak danych & $\begin{array}{l}0,625 \text { odchylenia stan- } \\
\text { dardowego }\end{array}$ \\
\hline Błąd nachylenia [mrad] & 0,1 & $\begin{array}{l}1,4 \text { (normalna do po- } \\
\text { wierzchni) }\end{array}$ & $\begin{array}{l}1,875 \text { (normalna do } \\
\text { powierzchni) }\end{array}$ \\
\hline Koszt (prod. 1/rok) & Brak danych & $380 \$ / \mathrm{m}^{2}$ & $275 \$ / \mathrm{m}^{2}$ \\
\hline Koszt (prod. 1000/rok) & Brak danych & $130 \$ / \mathrm{m}^{2}$ & Brak danych \\
\hline
\end{tabular}


Rysunki 3-5 przedstawiają wyżej sparametryzowane urządzenia

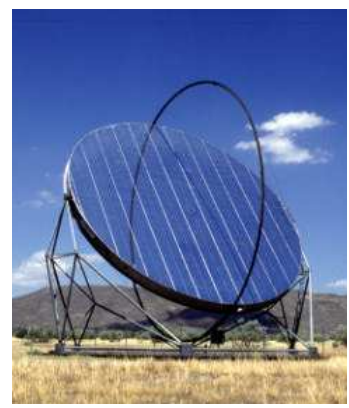

Rys. 3. Heliostat ASM 150, na podstawie [4]

Fig. 3. ASM 150 heliostat, based on [4]

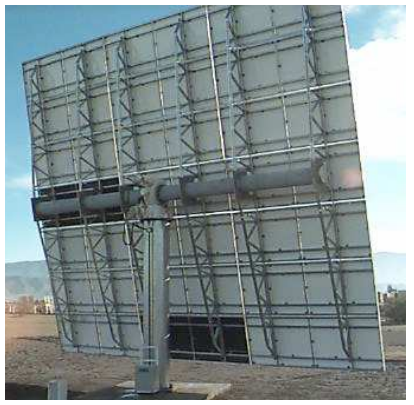

Rys. 4. Heliostat Colon 70, na podstawie [4]

Fig. 4. Colon 70 heliostat, based on [4]

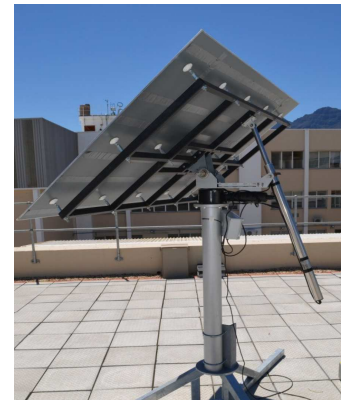

Rys. 5. Heliostat Helio 40, na podstawie [5]

Fig. 5. Helio 40 heliostat, based on [5]

\subsection{Struktura kosztów}

Koszt budowy heliostatu są ściśle uzależnione od jego wielkości i typu. Badania prowadzone nad optymalizacją budowy heliostatów nadal nie dały jednoznacznej odpowiedzi, jaka wielkość urządzenia przełoży się na najmniejszy koszt inwestycyjny całego pola. Stąd nadal podejmuje się decyzje inwestycyjne w kierunku heliostatów dużych, o powierzchni apertury $140-150 \mathrm{~m}^{2}$, a zarazem małych, o powierzchni $=<8 \mathrm{~m}^{2}$. Producentami tych pierwszych są m.in. Abengoa Solar, Sener oraz Pratt Whitney. Badania nad tymi ostatnimi podejmowane są zarówno w podmiotach prywatnych m.in. BrightSource $7 \mathrm{~m}^{2}$ czy eSolar $1 \mathrm{~m}^{2}$ jak i jednostkach naukowo badawczych: NREL (USA) $\sim 6 \mathrm{~m}^{2}$, DLR (Niemcy) $8 \mathrm{~m}^{2}$ oraz CSIRO (Australia) $4,5 \mathrm{~m}^{2}$. Każde z rozwiązań ma swoje wady i zalety, wszystkie nie na tyle istotne aby jedne zdominowały drugie. Stąd brak decyzji i równoległe prowadzenie badań $\mathrm{w}$ różnych kierunkach. Zgodnie $\mathrm{z}$ danymi z roku 2011 [6], dla dużych heliostatów największym kosztem jednostkowym są napędy azymutu i elewacji (24\%), zaplecze do budowy oraz zysk (21\%), zwierciadła (20\%) oraz konstrukcja nośna, podstawa i fundamenty (17\%). Dla małych heliostatów największą składową kosztów są również napędy (33\%), później zaplecze do budowy oraz zysk (25\%), okablowanie oraz układ kontroli położenia (20\%) oraz zwierciadła (18\%). Najważniejszym czynnikiem atmosferycznym wpływającym na budowę najbardziej kosztownych elementów heliostatu jest parcie powietrza na dużą płaszczyznę jaką zajmuje w przestrzeni zwierciadło. W światowych jednostkach naukowo badawczych przeprowadza się badania wpływu wiatru na napędy, konstrukcję nośną oraz zwierciadła. Stąd też wszelkie prace projektowe dla większości typów heliostatów rozpoczyna się od modelowania z wykorzystaniem narzędzi CAD oraz CFD właśnie tych zjawisk. Warunki graniczne są później przeniesione na rozwiązania techniczne poczynając od 
systemu awaryjnego ustawiania heliostat $\mathrm{w}$ pozycji bezpiecznej w przypadku wykrycia przekroczenia wartości krytycznych wymienionych w tab. 1 poprzez układy hamulców hydraulicznych, które sprzęgają (unieruchamiają) heliostat na czas występowania warunków niekorzystnych, kończąc na rozwiązaniach pośrednich tj. płoty (siatki) otaczające pole heliostatów, których głównym celem jest zmniejszenie siły jego parcia. W rezultacie otrzymujemy urządzenia, których aktualne ceny wahają się w granicach $150-200 \$ / \mathrm{m}^{2}$ natomiast cel światowych programów badawczych są ceny heliostatów na poziomie $75-120 \$ / \mathrm{m}^{2}$. Na Wydziale Energetyki i Paliw trwają testy heliostatu o kształcie sferycznym [7], który zapewni ochronę zwierciadła przed niekorzystnym oddziaływaniem warunków zewnętrznych przy jednoczesnym ograniczeniu siły parcia wiatru nawet dla większych płaszczyzn. Autorzy rozwiązania testują hipotezę, że sferyczny kształt heliostatu pomoże korzystnie rozłożyć składowe siły parcia wiatru, ułatwić czyszczenie i zminimalizować zabrudzenia przez łatwość odpływu wody deszczowej z kopuły osłonnej oraz uprościć konstrukcję mechaniczna elementów zastępujących siłowniki. Również przewiduje się, że koszty będą sporo niższe niż tradycyjnych rozwiązań. Rozwiązanie to jest chronione patentem [nr PL.220774]. Niestety pierwszy wariant nie zapewnił wystarczającej dokładności śledzenia, dlatego opracowany został wariant drugi, który jest obecnie w fazie pierwszych testów.

\section{Wnioski}

Heliostaty swoją konstrukcją i zasadą działania muszą być odporne na niekorzystne czynniki środowiskowe i atmosferyczne, zachować precyzję w swoim funkcjonowaniu przez minimum 30 lat, a jednocześnie być możliwie tanie gdyż są głównym składnikiem kosztów jednostkowych w trakcie budowy helioelektrowni typu wieżowego. Te trzy kryteria często działają kontradykcyjnie względem siebie stąd podejmowane są liczne próby optymalizacji poszczególnych elementów składowych heliostatów w różnych, czasem zupełnie rozbieżnych kierunkach. W konsekwencji, do dnia dzisiejszego, badane są zarówno urządzenia o powierzchni $150 \mathrm{~m}^{2}$ i wysokości $\sim 14 \mathrm{~m}$, a zarazem o pow. $1 \mathrm{~m}^{2}$ i wysokości $\sim 2 \mathrm{~m}$, ponieważ nadal nie stwierdzono jednoznacznie jakiej wielkości heliostaty są rozwiązaniem najbardziej optymalnym.

Badanie finansowane z grantu dziekańskiego na Wydziale Energetyki i Paliw Akademii Górniczo-Hutniczej w Krakowie, nr grantu: 15.11.210.332

\section{Literatura}

[1] Santelmann K.L., Wasyluk D.T., Sakadjian B.: Progress Towards Cost-Competitive Solar Power Tower Plants, zaprezentowano na: Power-Gen Middle East, Październik 12-14, 2014 Abu Dhabi, ZEA. 
[2] Pfahl A.: Survey of Heliostat Concepts for Cost Reduction, Journal of Solar Energy Engineering, vol. 136(1), 2013, ASME.DOI:10.1115/1.4024243.ISSN 0199-6231.

[3] Kolb G.J., Jones S.A., Donnelly M. W. i pozostali: Heliostat Cost Reduction Study, SANDIA REPORT SAND2007-3293, opublikowano Czerwiec 2007.

[4] Mancini T. R.: Catalog of Solar Heliostats, SolarPACES Technical Report No. III 1/00, opublikowano Czerwiec 2000.

[5] Larmuth J., Malan K., Gauché P.: Design and Cost Review of 2 m2 Heliostat Prototypes.

[6] Kolb G. J. i pozostali: Power Tower Technology Roadmap and Cost Reduction Plan, SAND2011-2419, opublikowano Kwiecień 2011.

[7] Wajss P., Filipowicz M. :A novel, spherical shaped sun tracker, Polska Energetyka Słoneczna ; ISSN 1730-2420. — 2013 nr 1-4, s. 33-38.

\section{HELIOSTATS' CHARACTERISTICS AND THEIR APPLICATION IN CENTRAL RECIVER-CONCENTRATED SOLAR POWER}

\section{S u m m a r y}

The development of a solar energy is associated with the development of new technologies, which maximize the utilization of the solar radiation. One direction is the solar radiation-heat conversion in the high temperature environment. From a thermodynamic point of view, this open new opportunities for power generation. The conversion, however, requires high concentration ratio of the solar radiation. There are many concentration techniques, but this article focuses on concentration on the top of the solar tower due to reflection from the heliostats' field. Such a system has several advantages in comparison to the small scale concertation systems. Mainly one high capacity power generation unit can be constructed. One of the main part of such system is heliostats' field. Article defines the concept of heliostat and presents the principles of its operation and its assignment in the Central Receiver Concentrating Solar Power (CR CSP). Different types of heliostats have been investigated and categorized. Factors that directly or indirectly affect the type, size and price of heliostats' parts have been described. The article presents a problem of the profitability of CR CSP and its relation with CAPEX of the heliostats' field. Detailed heliostats' requirements which must be fulfilled have been listed. Those have been divided into three groups: operational, optical and mechanical. Three significantly different by scale and type of operation examples of heliostats have been presented and parametrized in tabular form.

Keywords: solar power, concentrated solar radiation, sun tracking

Przestano do redakcji: 23.02 .2017 r.

Przyjęto do druku: 31.03.2017 r. 